\title{
Lean Six Sigma in a Call Centre: A Case Study
}

\author{
Alessandro Laureani (University of Strathclyde, Glasgow, UK) \\ Jiju Antony (University of Strathclyde, Glasgow, UK)
}

Alex Douglas (Liverpool Business School, Liverpool John Moores University, Liverpool, UK)

\begin{abstract}
Purpose
The case study illustrates the application of Lean Six Sigma in a Call Centre of a service industry corporation.

\section{Design/methodology/approach}

The study draws on process information and primary data from a real project.

\section{Findings}

The study describes improvements in the operation of the Call Centre attributable to Lean Six Sigma: increase in first-call resolution ratio, reduction in operator turnover and streamlining of processes.

\section{Practical implications}

The introduction of Lean Six Sigma into the Call Centre daily operations' management.

\section{Originality/value}

Although Lean Six Sigma has been extremely successful in the last two decades in the manufacturing sector, its applicability to the service sector has been a controversial topic. This study illustrates its application to a fast-growing area of the service sector, assisting companies in identifying areas of development for their Call Centres.
\end{abstract}

Keywords: Lean, Six Sigma, Call Centre, Quality, Process improvement 


\section{Introduction}

The objective of this paper is to demonstrate the power of Lean Six Sigma in a Call Centre environment and so challenge the myth that Lean Six Sigma is only applicable to manufacturing operations (Antony, 2007). A recent paper by McAdam et al. (2009) examined the role of Six Sigma in the measurement of Call Centre performance at strategic and operational levels but this paper goes beyond that to look at the impact of Lean Six Sigma on performance. Research questions include: Can Lean Six Sigma improve the operations of a Call Centre? What are the key opportunities and obstacles to its use in such a service oriented environment? As well as reference to the extant literature a case study detailing the application of the Lean Six Sigma methodology to a Call Centre environment will also be described and analyzed in order to address the research questions.

\section{What is Lean Six Sigma?}

Lean Six Sigma is a business improvement methodology that aims to maximize shareholder value by improving quality, speed, customer satisfaction and costs. It achieves these by merging tools and principles from both Lean and Six Sigma (George, 2003).

Lean and Six Sigma have followed independent paths since the 1980s, when the terms were first hard coded and defined: Lean originated in Japan (within the Toyota Production System); and Six Sigma began life in the US (within the Motorola Research Centre). 
- Lean is a process improvement methodology used to deliver products and services better, faster and at a lower cost. Womack and Jones (1996) defined it as "a way to specify value, line up value-creating actions in the best sequence, conduct those activities without interruption whenever someone requests them, and perform them more and more effectively. In short, lean thinking is lean because it provides a way to do more and more with less and less-less human effort, less human equipment, less time, and less space-while coming closer and closer to providing customers with exactly what they want."

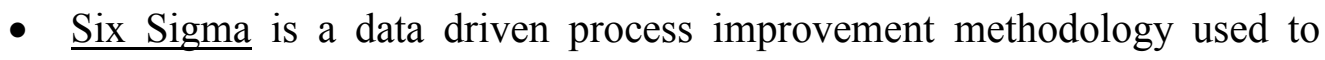
achieve stable and predictable process results, reducing process variation and defects: Snee (1999) defined it as "a business strategy that seeks to identify and eliminate causes of errors or defects or failures in business processes by focusing on outputs that are critical to customers".

While Lean is all about Speed and Efficiency, Six Sigma is about Precision and Accuracy: Lean ensures resources are working on the right activities while Six Sigma ensures things are done right the first time.

Lean Six Sigma uses tools from both toolboxes, in order to get the best of the two methodologies, increasing speed while also increasing accuracy (Mader, 2008). Benefits of Lean Six Sigma in the industrial world (both manufacturing and service) include: 
1. Ensuring services/products conform to what the customer needs (Voice of the Customer);

2. Removing non-value adding activities (waste);

3. Reducing the incidence of defective products/transactions;

4. Shortening cycle time;

5. Delivering the correct product/service at the right time in the right place.

Although used extremely successfully in manufacturing in the last two decades, the application of Lean Six Sigma in the service sector has been less tried and tested, amid fears that the processes in service industries do not lend themselves to the rigorous application of the set of statistical tools associated with Six Sigma (Patton, 2005)..

There are three main reasons why services need to apply Lean Six Sigma (George, 2003):

1. Service process can be slow and therefore costly, i.e. prone to error and therefore leading to reduced customer satisfaction;

2. Many service processes are complex and have too much "work-in-progress" which leads to increased waiting time - a non-value added cost;

3. The Pareto Principle applies to slow processes $-80 \%$ of the delay is caused by $20 \%$ of the activities. Therefore improving the speed of that critical $20 \%$ will lead to a reduction of $80 \%$ in cycle time.

The application of Lean Six Sigma in Call Centres has been even more controversial in the last few years, with some practitioners envisaging a large amount of 
opportunities, but with others doubting the feasibility of its application to such an environment.

\section{Why Apply Lean Six Sigma in a Call Centre?}

Call Centres are a worldwide phenomenon. Countries such as the Netherlands, Ireland, UK, Philippines, South Africa and India all have large Call Centre industries. In the US there are over 55,000 Call Centres employing approximately 2.9 million agents (Mahesh and Kasturi, 2006). In the UK the sector employs over 595,000 agents in 6324 Call Centres (Mintel, 2009).

The two major types of Call Centres are outbound centres and inbound centres. The most common are inbound Call Centre operations. For many customers Call Centres are the first point of contact with an organisation and their experiences can play a major role in their decision to stay or leave that organisation (Taylor et al, 2003). Almost everyone in their daily life has had the experience of contacting one of those Centres for a variety of reasons. In the UK alone, more than 10 million customers use telephone banking (Forsyth, 2004).

Outbound centres are used more in areas such as marketing, sales and credit collection. In those cases, it's the Call Centre operator that makes contact with the user/customer. Although there are some differences between outbound and inbound call centres, they each have similar potential benefits and challenges for the implementation of Lean Six Sigma.

\section{Benefits}


Some of the benefits that Lean Six Sigma can deliver in a Call Centre are given below (Jacowski, 2008; Gettys, 2009)::

1. Streamlining the operations of the Call Centre: Lean strategy helps in eliminating waste and other non-value added activities from the processes;

2. Decreasing the number of lost calls: Six Sigma's root cause analysis and hypothesis testing techniques can assist in determining how much time to spend on different type of calls thus providing a guide to the operators;

3. Better utilization of resources (both human resource and technology), leading to a reduction in the costs of running the Call Centres;

4. Unveiling the 'hidden factory': establishing the root causes of why customers call in the first place, can help in uncovering troubles further up in the process stream thus providing benefits that go further than the Call Centre itself and improving customer service and support;

5. Reducing employees' turnover: Call Centres are usually characterized by high employee turnover, due to the highly stressful work environment (Mintel, 2009). A more streamlined operation would assist in reducing operators' stress, particularly in an in-bound Call Centre.

\section{Challenges}

Specific challenges to apply Lean Six Sigma in a call centre environment are given below (Piercy and Rich, 2009):

1. The relentless pace of the activity (often 24/7) makes it more difficult for key elements of staff to find the time to get involved in projects and Lean Six Sigma training; 
2. The realization of an appropriate Measurement System Analysis (MSA) (Wheeler \& Lyday, 1990) is made difficult from the inherent subjectivity and interpretation of some call types thus failing reproducibility tests among different Call Centre operators;

3. High employee turnover, that normally characterizes Call Centres, make it more difficult for a Lean Six Sigma program 'to stick' in the organization.

\section{A SWOT Analysis}

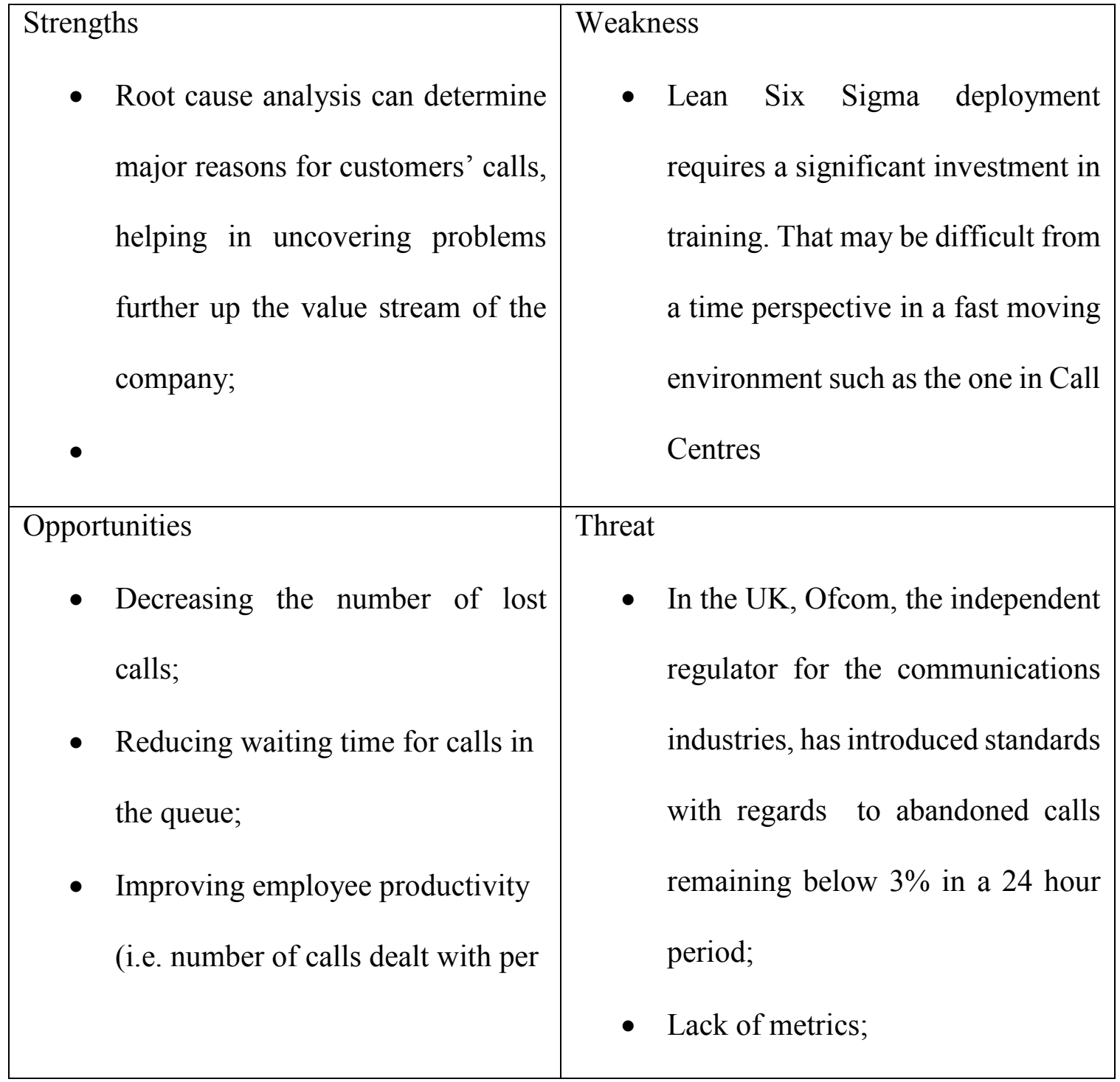




\begin{tabular}{|l|l|l|}
\hline the hour) & $\begin{array}{l}\text { Lack of support from process } \\
\text { owner; }\end{array}$ \\
& - Pre-conceived ideas. \\
\hline
\end{tabular}

Overall, the opportunities far outweigh the challenges. Call Centres nowadays are more than just operations: they are the first, and sometime only, point of contact a company may have with its customers. Their efficient and effective running through timely resolution of customers' queries can go a long way in establishing the company's brand and image.

\section{Lean Six Sigma Projects in Call Centres}

Project selection is a critical component of success: not all projects may be suitable candidates for the application of Lean Six Sigma, and this needs to be kept in mind while assessing the operation of a Call Centre. Also, different tools and techniques may be more suitable to a specific project, depending on the nature and characteristic of the process it is trying to address.

Projects that better lend themselves to Lean Six Sigma share, inter alia, the following characteristics:

- The focus of the project is on a process that is either not in statistical control (unstable) or outside customer specifications (incapable). As already mentioned in the introduction, Six Sigma techniques focus on reducing the variation in a process, making them the ideal tools for tackling an incapable but stable process, while the Lean tools 
focus more on the elimination of waste and would be the first port of call for streamlining an unstable process. Priorities should be given to unstable processes, using Lean tools to eliminate the wastes and simplify the process: once it has stabilized, more advanced statistical tools, from the Six Sigma toolbox, can be used to reduce variation and make the process capable.

- The root reason(s) for this has not been identified yet: it is important to start work on the project with a clear state of mind and without any prejudice. Data and hard facts should guide the project along its path;

- Quantitative metrics of the process are available: lack of measures and failing to realize a completed Measurement System Analysis (MSA) (Wheeler and Lyday, 1990) can seriously jeopardize any improvement effort

- The process' owner is supportive and willing to provide data and resources: this is critical for the on-going success of the project, and the process owner role is discussed in detail in the Control Phase section

Example of projects

Potential areas of focus for Lean Six Sigma projects in Call Centres are:

- Lost calls ratio out of total calls for an inbound call centre;

- Customers' waiting/holding times for an inbound call centre;

- First-Call resolution;

- Calls-back inflating call volumes. 


\section{Case Study}

The case study focuses on a large corporation in the service sector operating in the vehicle leasing and renting industry: it sells its services to both the general retail public and other businesses in 145 countries and has 22,000 employees and 8,000 locations.

Its European Call Centre was receiving an average of 10,000 calls a month from customers who had an issue with either the level of service received or the billing/invoicing process.

The company puts a lot of emphasis on its level of customer service, an integral part of its mission, vision and values, as a differentiator from the competition; its strategic position was that of a quality service, intended to attract those customers who wanted to pay a bit more for a better service, in contrast with its low-cost competitors. Consequently, quality of customer service was a critical component of the company's strategy: the number of calls received and the more frequent issues reported by customers were continuously analysed and employees' variable compensation linked to it. The number of contacts received from customers amounted to about $2 \%$ of the total transactions (five million a year). The specific objective of the inbound Call Centre was to deal as quickly and efficiently as possible with those customers.

\section{Problem Statement}

A consistent number of the calls of the 1,200,000 received annually at the inbound Call Centre couldn't be solved at the first attempt, leading to customer dissatisfaction and 
unnecessary repetition of work in the Centre. The objective of the project was to increase the first-call resolution ratio.

\section{Define Phase}

A cross-functional project team was created, led by a Black Belt, with the objective of using the DMAIC (Define, Measure, Analyse, Improve, and Control) Six Sigma breakthrough methodology in order to increase the first-call resolution ratio. The team scoped down the project, identifying which specific areas of the Call Centre and services they were going to focus on; a high-level process map or SIPOC (Suppliers, Inputs, Process, Outputs, Customers) (Pyzdek, 2003) was created, followed by a more detailed process map (see figures 1 and 2 below).

\begin{tabular}{|c|c|c|c|c|c|c|}
\hline Suppliers & Inputs & \multicolumn{2}{|c|}{ Process } & Outputs & \multicolumn{2}{|c|}{ Customers } \\
\hline $\begin{array}{c}\text { (Providers of the required } \\
\text { resources) }\end{array}$ & $\begin{array}{c}\text { (Resources required by the } \\
\text { process) }\end{array}$ & \multicolumn{2}{|c|}{$\begin{array}{c}\text { (Top level description of the } \\
\text { activity) }\end{array}$} & (Deliverables from the process) & \multicolumn{2}{|c|}{$\begin{array}{c}\text { (Anyone who receives a } \\
\text { deliverable from the process) }\end{array}$} \\
\hline \multirow{5}{*}{ Customer (Retail or Business) } & & Requirements & & & Requirements & \\
\hline & Request info on service/billing & Dates / Times & \multirow{4}{*}{$\begin{array}{c}\text { Immediate } \\
\text { compensation } \\
\text { resolution or } \\
\text { escalation for } \\
\text { further } \\
\text { investigation }\end{array}$} & \multirow{3}{*}{$\begin{array}{l}\text { Service } \\
\text { Time to handle call }\end{array}$} & $\begin{array}{l}\text { Professional } \\
\text { and corteous }\end{array}$ & Customer \\
\hline & & Location & & & minutes & Customer \\
\hline & & Reservation ID & & & $\begin{array}{l}\text { Service that } \\
\text { makes } \\
\text { customer use } \\
\text { company again }\end{array}$ & $\begin{array}{l}\text { Company's } \\
\text { Senior } \\
\text { Managemnt }\end{array}$ \\
\hline & & $\begin{array}{l}\text { Description of } \\
\text { Events }\end{array}$ & & Time to handle call & $\begin{array}{l}\text { To maintain } \\
\text { waiting queues } \\
\text { to }<2 \text { minutes }\end{array}$ & $\begin{array}{l}\text { Call Centre } \\
\text { Manager }\end{array}$ \\
\hline
\end{tabular}

Figure 1: SIPOC (High Level Process Map) 


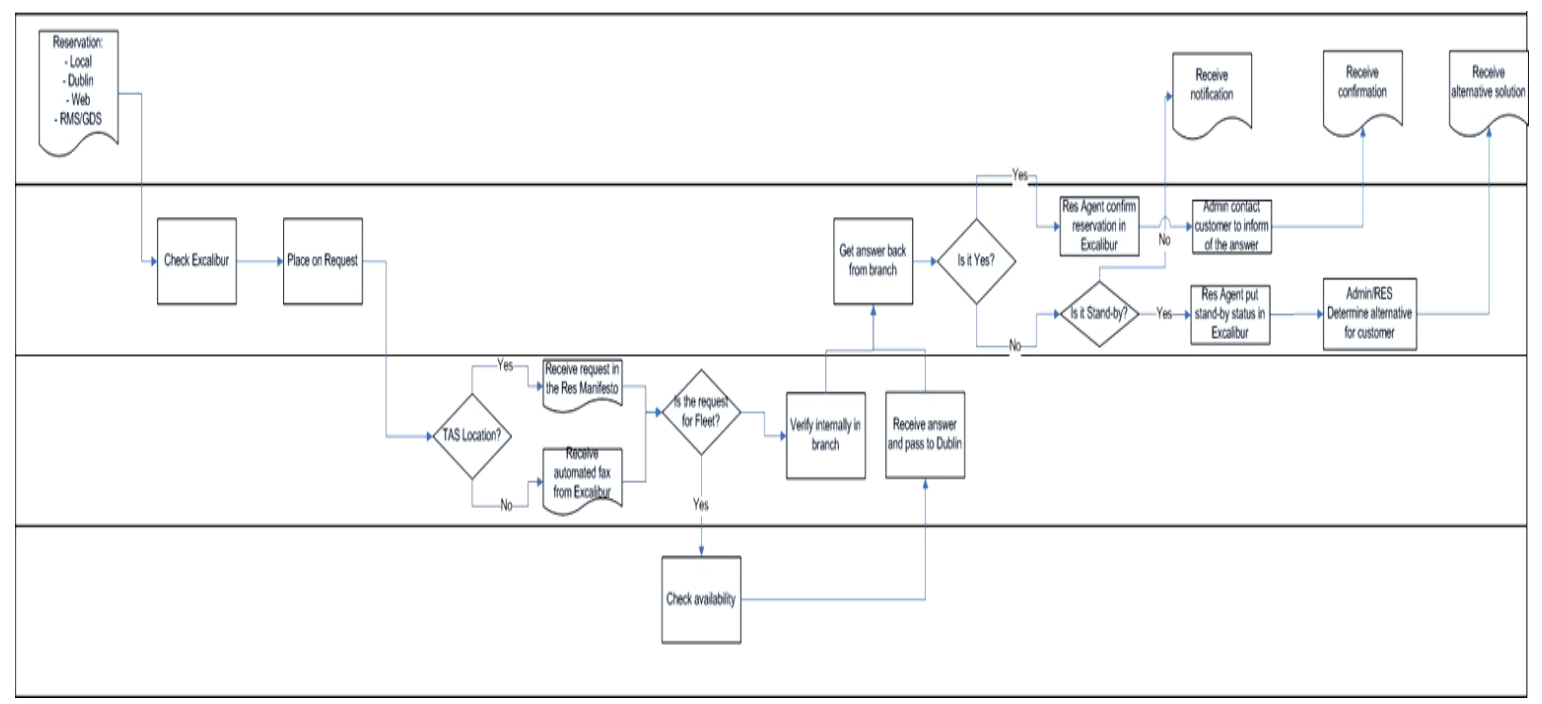

Figure 2: Detailed Process Map

The team also investigated the seven kinds of waste accordingly to Lean principles.

These are:

1. Overproduction

2. Inventory

3. Motion

4. Waiting

5. Transportation

6. Over-processing

7. Defects

Of these seven wastes, four were identified as belonging to the current state of the process:

- Motion: unnecessary movement from the Call Centre operators, who needed to leave their workstation to perform some routine tasks, e.g. sending/receiving a fax, printing a document; 
- Waiting: sometimes an operator could not answer a customer's query immediately because they were waiting for an answer from another department or a supervisor;

- Over-processing: some of the queries from customer couldn't be addressed on the phone and needed to be dealt with off line by another operator, so creating unnecessary re-work and reducing customer satisfaction;

- Defects: a query was not always completely solved the first time, forcing customers to call back and so creating unnecessary work and lowering customer satisfaction.

To complete the Define Phase, the operational definition of first-time call resolution was developed and agreed with the major stakeholders: a call was deemed not resolved if, at the end of it, the case was still open in the Customer Relationship Management system, or was escalated or transferred to another department.

\section{Measure Phase}

In this phase the project team established the key metrics for the process and calculated the baseline performances of the process at the start of the project. The DPMO (Defects Per Million Opportunities) value of the process was calculated (Pyzdek, 2003), using random sampling techniques (see Table 1 below): establishing this is a key component of the Measure Phase, as it becomes the benchmarking performance measure against which the project will be evaluated. 


\begin{tabular}{|l|l|}
\hline Total Number of Calls Received & 91,134 \\
\hline Unresolved Queries after First Call & 10,769 \\
\hline Unresolved as \% of Total Calls & $11.82 \%$ \\
\hline DPMO & 118,167 \\
\hline
\end{tabular}

Table 1: DPMO Value Calculations at the start of the project

It is important to note at this stage that, whatever the measurement system agreed upon, it must be kept consistent at the end of the project, so the pre- and post-project performances of the process can be compared.

Analyze Phase

The team went into the details of the data, slicing them across different dimensions, and noted, using a Pareto Chart (see figure 3 below), which two types of queries accounted for about $70 \%$ of the unresolved first-time calls: 


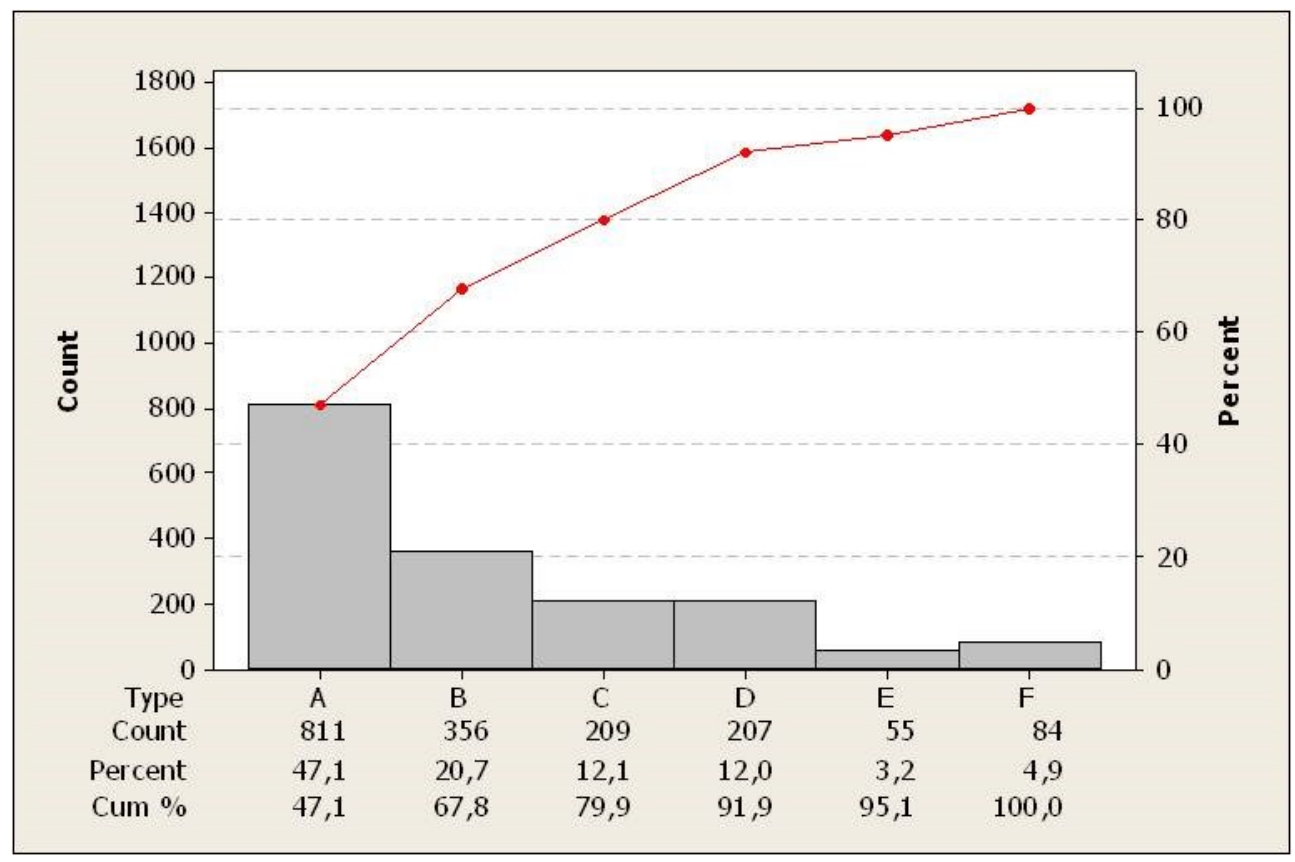

Figure 3: Pareto Chart of Unresolved First-Time Calls by Type of Query (Column ' $F$ ' is 'all other types')

Hypothesis tests showed no relationship between the number of unresolved firsttime calls and the Call Centre operators: in other words, there was no statistically significant difference in the number of unresolved first-time calls between more experienced and less experienced operators. As a result, the focus was put on eliminating the root causes for categories " $\mathrm{A}$ " and "B" of the queries.

\section{Improve Phase}

While collecting and analysing the data, the project team had the chance to "walk the process", i.e. observe the process in action: this allowed them to identify two so called 
"quick win" actions (actions that can be easily implemented without roadblocks or concerns). Two improvement ideas were also generated in a brainstorming session.

All those actions were first pre-tested through a pilot group, in a sub-section of the overall Call Centre: further data were collected from the pilot group to quantify the effects of the improvement actions.

The sigma value for the new process, after the improvements were implemented, was recalculated in the pilot group (see Table 2 below).

\begin{tabular}{|l|l|}
\hline Total Number of Calls Received & 27,385 \\
\hline Unresolved Queries after First Call & 2,315 \\
\hline Unresolved as \% of Total Calls & $8.45 \%$ \\
\hline DPMO & 84,535 \\
\hline
\end{tabular}

Table 2: DPMO Value Calculations after improvement actions are implemented

Based on the sample size results on the pilot group, the improvement actions reduced the percentage of unresolved first-time calls from $11.82 \%$ to $8.45 \%$. This was deemed satisfactory and the improvement actions were rolled out to the whole Call Centre.

\section{Control Phase}

As part of the Control Phase, the project team documented the improvement actions implemented in a control plan, which was then handed over to the process owner to ensure sustainability of the process going forward. 
A "p-chart" was used to monitor and sustain the gains (see figure 6 below).

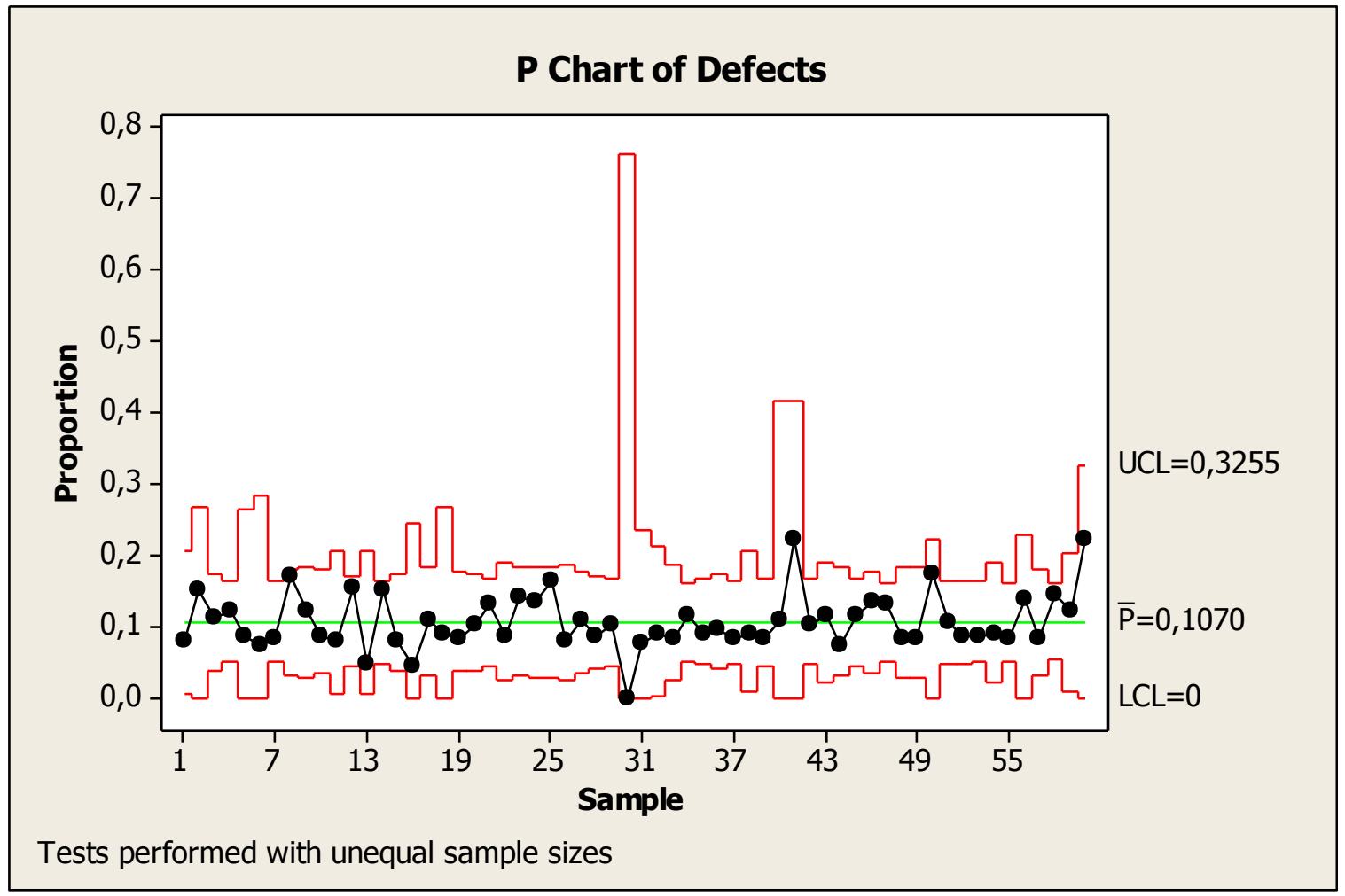

Figure 6: P Control Chart

The team also calculated the financial impact of the project. Calculating this in a Call Centre can be tricky, due to the confusion normally existing between so called 'hard savings' and 'soft savings': the first are those financial values identifiable in the Profit and Loss account and Balance Sheet of the organization (e.g. payroll costs, telecommunication costs, hardware, software), whereas the latter are not listed in the balance sheet (e.g. productivity increase, customer satisfaction).

The 3\% decrease in un-resolved queries after first contact resulted in 36,000 fewer calls to the Call Centre on an annual basis $(36,000=3 \%$ of $1,200,000$, as this was the number of calls expected to be handled annually). 
This freed a certain amount of resources, in terms of both staff and telecommunication equipment, whose value was estimated at about $\$ 200,000$ per annum.

\section{Managerial Implications and Key Lessons Learned}

The main managerial implications from the project were in terms of management's approach to Lean Six Sigma and communication.

The success of this particular project made Senior Management aware of the opportunities the application of Lean Six Sigma created in the Call Centre environment. Better utilization of resources, reduced operational costs and improved customer service are vital factors for the long term sustainability of a Call Centre: plans for further Lean Six Sigma projects were prepared.

In terms of communication, the most relevant aspect was related to employees' informal communication: the member of the cross-functional project team, working along with the Black Belt, were exposed to some of the Lean Six Sigma tools and could see their impact on the understanding of the process. Some of them went proceeded to apply for Six Sigma Green Belt training, fostering a culture of continuous improvement in the organization and getting more staff involved in the Lean Six Sigma program.

The key lessons to be learned from this case study are related to the first phase (Define) and the last phase (Control) of project:

1. The fact that no stakeholder analysis was performed in the Define Phase may not have caused major problems in this particular project, where the Call Centre was physically in one unique location, but given the spread of 
operations across the world, the importance of conducting a proper Stakeholder analysis at the outset of the project must be emphasised

2. In the Control Phase, the completed control plan was handed over to the process owner to ensure sustainability of the process going forward. However, it may be necessary for the Black Belt, after a certain time, to revisit the process, to ensure improvement actions are still in place, and the process had not reverted to its pre-project status.

\section{Conclusion}

Call Centres are increasingly important for many businesses and are consistently struggling with the pressure of delivering a better service at a lower cost. This paper tried to address the issue of whether Lean Six Sigma can be useful in a Call Centre environment: by means of a Case Study, it was found that Lean Six Sigma can improve the operation of

a Call Centre, through an increase in First-Call resolution (that reduces failure created by failing to answer the query in the first place), a reduction in Call Centre operators' turnover (leveraging on training and experience) and streamlining the underlying processes by eliminating unnecessary operations.

The Case Study illustrated within this paper has used a certain number of the tools available in the Lean Six Sigma toolbox, while omitting some other important tools (e.g. stakeholder analysis and measurement system analysis): however, despite this, it managed to improve the First-Call resolution, and hence the customer service levels, of its operation. 
Given the large scale of many Call Centre operations, even a relatively small improvement in the sigma value of the process can dramatically reduce the defect rate, increase customer satisfaction and deliver financial benefits to the bottom-line.

By focusing on eliminating waste, identifying the truly value adding activities and using the DMAIC tools for problem solving, it is possible to achieve significant improvements in costs and the levels of customer service provided (Swank, 2003). 


\section{References}

- Antony, (2007) "Six Sigma in service organizations. Benefits, challenges and difficulties, common myths, empirical observations and success factors". International Journal of Quality and Reliability Management, Vol. 24, No. 3, pp. 294-311.

- Forsyth, A.M. (2004) Lloyds TSB Banks on Call-Center Quality, Human Resource Management International Digest, Vol. 12, No. 1, pp. 14-16.

- Gettys, R. (2009) "Using Lean Six Sigma to improve Call Center operations". Retrieved Jan 22, 2009 from http://finance.isixsigma.com/library/content/c070418a.asp

- George, M.L. (2003) Lean Six Sigma For Services, McGraw-Hill, New York.

- Jacowski, T. (2008) "Maximizing Call Center resource utilization with Six Sigma". Retrieved Jan 22, 2009 from http://ezinearticles.com/?Maximizing-Call-Center$\underline{\text { Resource-Utilization-With-Six-Sigma\&id=1014905 }}$

- Mader, D. P. (2008) “Lean Six Sigma’s evolution”, Quality Progress, Vol. 41, No. 1, pp. 40-48.

- Mahesh, V.S. and Kasturi, A. (2006) Improving Call Centre Agent Performance: A UK-India Study Based on the Agents' Point of View, International Journal of Service Industry Management, Vol. 17, No.2, pp. 136-157.

- McAdam, R., Davies, J., Keogh, B. And Finnegan, A. (2008) Customer-Oriented Six Sigma in Call Centre Performance Measurement, International Journal of Quality and Reliability Management, Vol.26, No.6, pp. 516-645.

- Mintel (2009) Call Centre Industrial Report, April.. 
- Patton, F. (2005) “Does Six Sigma work in service industries?”, Quality Progress, Vol. 38, No. 9, pp. 55-60

- Piercy, N. \& Rich, N. (2009) "Lean transformation in the pure service environment: the case of the call centre", International Journal of Operations \& Production Management, Vol. 29, No. 1, pp. 54-76.

- Pyzdek, T. (2003) The Six Sigma Handbook, McGraw-Hill Professional, New York.

- Rosenberg, A. (2005) "Six Sigma: the myth, the mystery, the magic - Can Six Sigma really make an impact in your call center?’. Retrieved Jan 22, 2009 from http://www.callcentermagazine.com/shared/article/showArticle.jhtml?articleId=5 $\underline{9301130}$

- Snee, R. D. (1999) "Why should statisticians pay attention to Six Sigma?", Quality Progress, Vol. 32, No. 9, pp. 100-103

- Taylor, P., Baldry, C., Bain, P. And Ellis, V. (2003) A Unique Working Environment: Health, Sickness and Absence Management in UK Call Centres, Work, Employment and Society, Vol.17, No.3, pp. 435-458.

- Wheeler, D. J. And Lyday, R. W. (1990) Evaluating the Measurement Process. 2nd edition. SPC Press.

- Womack, J. P. \& Jones, D. T. (1996), Lean Thinking, Free Press 